\title{
On the Involvement of Singlet Oxygen in the Biosynthesis of Oxygenation Products of the Furocoumarin Imperatorine
}

\author{
Nicolaas J. de $\mathrm{Mol}^{\mathrm{a}, *}$, Johannes Reisch ${ }^{\mathrm{b}}$, \\ and Gerardus M. J. Beijersbergen van Henegouwen ${ }^{a}$ \\ a Department of Pharmacochemistry, Subfaculty of Pharmacy, State University of Leiden, \\ Gorlaeus Laboratories, P. O. Box 9502, 2300 RA Leiden, The Netherlands \\ b Institute of Pharmaceutical Chemistry, Westfalian Wilhelms University, \\ Hittorfstraße 58-62, 4400 Münster, Federal Republic of Germany
}

Z. Naturforsch. 39b, 1433-1441 (1984); received December 12, 1983

Singlet Oxygen, Biosynthesis, Imperatorine, Isogosferol, Photo-oxygenation

The role of singlet oxygen $\left({ }^{1} \mathrm{O}_{2}\right)$ in the photo-oxidation of the furocoumarin imperatorine was investigated in vitro. Irradiation with visible light and sensitization with methylene blue yielded the imperatorine oxidation product isogosferol and the corresponding ketone as main products. The involvement of ${ }^{1} \mathrm{O}_{2}$ was demonstrated by studying the rate of oxidation under conditions that affect the lifetime of ${ }^{1} \mathrm{O}_{2}$. Compared to a range of other furocoumarins, imperatorine appeared to be moderately active as a ${ }^{1} \mathrm{O}_{2}$ generator. The extent of ${ }^{1} \mathrm{O}_{2}$ production correlated with the skin sensitizing activity. Upon irradiation of imperatorine itself with UVA light $(360 \mathrm{~nm})$ no isogosferol formation is observed, probably as a consequence of its photochemical instability. Irradiation with visible light $(\lambda>400 \mathrm{~nm})$ of a chlorophyll chromophore containing sensitizer in the presence of imperatorine, yielded isogosferol and the corresponding ketone product. This demonstrates that in the formation of ${ }^{1} \mathrm{O}_{2}$ oxidation products of imperatorine in plants naturally occuring sensitizers e.g. chlorophyll and visible light are involved, rather than ${ }^{1} \mathrm{O}_{2}$ produced by imperatorine or other furocoumarins and UVA light. The protective effect on the chlorophyll sensitized imperatorine oxidation by the ${ }^{1} \mathrm{O}_{2}$ - and chlorophyll triplet quencher $\beta$-carotene was demonstrated in a lipophilic solvent.

\section{Introduction}

The involvement of non-enzymatic photochemical reactions in the biosynthesis of secondary plant occuring compounds forms a rather unexplored field of research. There are some indications that such photoreactions are probable. However, the literature also contains indications that light induced processes first occur during handling of the plant material. As a consequence in this case compounds considered as genuine natural products are in fact artefacts (e.g. Andrada et al. [1], Reisch and Szendrei [2], Herlem et al. [3] and Kusumi et al. [4]). Another complication in the question whether nonenzymatic photochemical reactions play a role is the fact that there can be parallels between the photochemistry of a natural product and its metabolism (Singh et al. [5]).

In the last decades progress is made in the field of cellular photo-oxygenation, also thanks to the pioneering of G. O. Schenk [6]. From this it appeared that photo-oxygenations can be steps in biosynthesis pathways. To an increasing extent it is

\footnotetext{
* Reprint requests to Dr. Nicolaas J. de Mol. $0340-5087 / 84 / 1000-1433 / \$ 01.00 / 0$
}

attempted to simulate these steps with the aid of biomimetic experiments (Matsuura [7]).

The presence of isogosferol (III) and gosferol (IV) in plants prompted us to investigate whether these oxidation products of imperatorine (I) and isoimperatorine (II) respectively, can be formed from non-enzymatic dyesensitized photo-oxygenation.

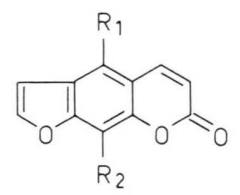

I Imperatorine

$$
\mathrm{R}_{1}=\mathrm{H}, \mathrm{R}_{2}=\mathrm{O}-\mathrm{CH}_{2}-\mathrm{CH}=\mathrm{C}\left(\mathrm{CH}_{3}\right)_{2},
$$

II Isoimperatorine $\mathrm{R}_{1}=\mathrm{O}-\mathrm{CH}_{2}-\mathrm{CH}=\mathrm{C}\left(\mathrm{CH}_{3}\right)_{2}, \mathrm{R}_{2}=\mathrm{H}$,

III Isogosferol $\mathrm{R}_{1}=\mathrm{H}, \mathrm{R}_{2}=\mathrm{O}-\mathrm{CH}_{2}-\mathrm{CH}(\mathrm{OH})-\mathrm{C}\left(\mathrm{CH}_{3}\right)=\mathrm{CH}_{2}$,

IV Gosferol

$$
\mathrm{R}_{1}=\mathrm{O}-\mathrm{CH}_{2}-\mathrm{CH}(\mathrm{OH})-\mathrm{C}\left(\mathrm{CH}_{3}\right)=\mathrm{CH}_{2}, \mathrm{R}_{2}=\mathrm{H} \text {. }
$$

Isogosferol and gosferol have been observed together with imperatorine and isoimperatorine in species of Prangos (Abyshev [8-10]; Chatterjee et al. [11]), Ruta (Gonzalez et al. [12]), Heracleum (Gonzalez et al. [13]) and Peucedanin (Gonzalez et al. [14]; Varga et al. [15]). 
Considering the side-chain of isogosferol, this corresponds with the modification of the side-chain of imperatorine that can be expected as a result of an ene-reaction of ${ }^{1} \mathrm{O}_{2}$ with imperatorine. Ene-reactions with alkyl-substituted olefins are quite characteristic for ${ }^{1} \mathrm{O}_{2}$. The inevitably shifted double bond clearly distinguishes the ene-type reaction from the well-known autoxidation reaction (Gollnick and Kuhn [16]).

${ }^{1} \mathrm{O}_{2}$ is a short living excited form of oxygen, a reactive intermediate with a life time in water of $2 \mathrm{msec}$. In the last decade biochemists and biologists have become interested in ${ }^{1} \mathrm{O}_{2}$ chemistry because of the possible role that this species plays in biological systems; for a review see Krinsky [18]. Compounds I to IV are members of an extended family of naturally occuring furocoumarin compounds. A series of photobiologically active furocoumarins, including the therapeutically important compounds 8 -methoxypsoralen and 4,5',8-trimethylpsoralen, are able to generate ${ }^{1} \mathrm{O}_{2}$ upon irradiation with UVA light (de Mol et al. [17]). This occurs via energy transfer from the photo-activated sensitizer i.e. the psoralen compounds. This is a common process with which a wide variety of photobiologically active sensitizers such as acridines, porphyrones, methylene blue and proflavine generate ${ }^{1} \mathrm{O}_{2}$.

In the present study the possibility was investigated that isogosferol is formed from imperatorine by ${ }^{1} \mathrm{O}_{2}$ oxidation. Further, investigations were directed to the possible source of ${ }^{1} \mathrm{O}_{2}$ responsible for the oxidation of imperatorine in plants: the furocoumarin part of the imperatorine molecule and/or other sensitizers especially the chlorophyll chromophore.

\section{Materials and Methods}

\section{Materials}

\section{Imperatorine}

Imperatorine was collected as a result of many photochemical investigations on the roots of different species of the families Rutaceae and Umbelliferae in our laboratories (see e.g. J. Reisch et al., Planta Med. 43, 225 (1981)).

The following compounds were used as purchased: methylene blue (Aldrich), 1,4-diazabicyclo[2.2.2.]octane (DABCO) (Aldrich), deuteriumoxide (Aldrich, 99.8\%), chlorophyll (Brocacef, technical product, oil soluble paste) (see Merck Index, 9th ed., p. 2137). Estimation of chlorophyll content based on molar absorptivity of chlorophyll at $660 \mathrm{~nm}$ in ether is $8.63 \times 10^{4} 1 \cdot \mathrm{mol}^{-1} \cdot \mathrm{cm}^{-1}$ and ratio chlorophyll $\mathrm{a}: \mathrm{b}=$ $3: 1$. Chlorophyllin (copper complex of the sodium salt of chlorophyllin, $100 \%$ according to NMR, water soluble) (Merck). $\beta$-Carotene (Fluka, purum). L-3,4-dihydroxyphenylalanine (DOPA) (GistBrocades, pharmaceutical quality).

\section{Preparative methylene blue sensitized irradiation of imperatorine}

$100 \mathrm{ml}$ of a solution of $0.4 \mathrm{mM}$ methylene blue and $7.3 \mathrm{mM}$ imperatorine in methanol was placed in a glass tube i.d. $2.0 \mathrm{~cm}$. This tube was surrounded by $2.0 \mathrm{~cm}$ of a filter solution containing $0.1 \% \mathrm{~K}_{2} \mathrm{Cr}_{2} \mathrm{O}_{7}$ which cuts off wave lengths $<440 \mathrm{~nm}$. The stirred solution was irradiated with a $1000 \mathrm{~W} \mathrm{HgXe} \mathrm{lamp}$ model 6295 (Oriel Co.) mounted in an Oriel lamp house with continuous oxygenation. The decomposition of imperatorine was monitored by means of HPLC analysis. After a total irradiation time of $24 \mathrm{~h}$ $\sim 70 \%$ of the imperatorine was decomposed. The solvent was evaporated to $\sim 3 \mathrm{ml}$ and the residue was applied to a silicagel column (Merck kieselgel-60, $70-230$ mesh ASTM, length $20 \mathrm{~cm}$, i.d. $4 \mathrm{~cm}$ ). The column was eluted with toluene/chloroform $=7 / 3$. HPLC analysis showed that after passage of $\sim 2000 \mathrm{ml}$ with a flow of $5 \mathrm{ml} / \mathrm{min}$ a fraction was obtained containing non-converted imperatorine next to a fraction containing a mixture of 3 main products.

\section{Preparative HPLC separation}

The fraction containing the 3 products was evaporated and the residue dissolved in $5 \mathrm{ml}$ methanol. Samples of $0.5 \mathrm{ml}$ were injected into a Spectra Physics SP 3500 B Liquid Chromatograph equipped with a preparative column filled with lichrosorb RP 18, $10 \mu, 1=30 \mathrm{~cm}$, i.d. $=2.0 \mathrm{~cm}$ (Chrompack) connected to a UV detector LKB model no. 2138 with a $280 \mathrm{~nm}$ filter. The eluent was $\mathrm{MeOH} / \mathrm{H}_{2} \mathrm{O}=65 / 35$, flow $8 \mathrm{ml} / \mathrm{min}$. The 3 products were collected separately and were analysed after evaporation of the solvent by means of NMR (Jeol JNM PS-100, solvent $\mathrm{CD}_{3} \mathrm{OD}$ with TMS as reference), IR (Infrared spectrophotometer Pye Unicam SP 3-200) and mass spectrometry (AEI MS-20 mass spectrometer, source operating at $70 \mathrm{eV}$, source temperature $\sim 200{ }^{\circ} \mathrm{C}$ with heated direct inlet system $\sim 150{ }^{\circ} \mathrm{C}$.

\section{Analytical irradiations}

Methylene blue, chlorophyll and chlorophyllin sensitized irradiations were performed with the 
$1000 \mathrm{~W} \mathrm{HgXe} \mathrm{lamp} \mathrm{in} 3 \mathrm{ml}$ quartz cuvets with continuous oxygenation. In the case of methylene blue a filter solution was applied of $1 \mathrm{~cm}$ path length containing $0.1 \% \quad \mathrm{~K}_{2} \mathrm{Cr}_{2} \mathrm{O}_{7}$ cutting off wavelengths $<440 \mathrm{~nm}$. In the case of chlorophyllin and chlorophyll the filter was $0.1 \% \mathrm{~K}_{2} \mathrm{CrO}_{4}$ cutting off wavelengths $<400 \mathrm{~nm}$. For further details see legends of the Figures. Direct irradiation of imperatorine solutions were performed with RUL $3500 \AA$ lamps mounted in a Rayonet Photochemical Reactor (Southern New England Ultra Violet Co.). Light intensities were measured with a UVX Radiometer equipped with a UVX-36 sensor (UltraViolet Products Inc.). Ten $\mathrm{ml}$ of the solutions in square quartz tubes $(1 \times 1 \times 15 \mathrm{~cm})$ were placed in a caroussel in the photochemical reactor. The ${ }^{1} \mathrm{O}_{2}$ acceptor DOPA was assayed according to a procedure previously described (de Mol et al. [19]). For further details see legends of the Figures.

\section{HPLC analysis}

Samples of $10 \mu \mathrm{l}$ were injected in the liquid chromatograph (for details see under Preparative HPLC separation). The column was filled with Lichrosorb $5 \mu$ RP $18,1=15 \mathrm{~cm}$, i.d. $=4.6 \mathrm{~mm}$ (Chrompack Stock Column). The eluent was methanol $/ \mathrm{H}_{2} \mathrm{O}=2 / 1$, flow $1.4 \mathrm{ml} / \mathrm{min}$. Retention times for imperatorine, isogosferol, isogosferone and xanthotoxol were $10.8,4.8,4.4$ and $2.4 \mathrm{~min}$, respectively.

\section{Results and Discussion}

From a solution of imperatorine with methylene blue as sensitizer irradiated with visible light $(\lambda>440 \mathrm{~nm})$ three products have been isolated and identified. Methylene blue was chosen as sensitizer, because it is an efficient ${ }^{1} \mathrm{O}_{2}$ generator: oxygen quenching is the only important decay mode for triplet methylene blue in dilute solutions $(\sim 0.02 \mathrm{mM})$ (Merkel and Kearns [20]). Identification of the products is reported in the order of HPLC elution.

The $100 \mathrm{MHz}$ NMR spectrum of product 1 showed the typical pattern of the intact furocoumarin structure: 2 doublets with small coupling constants at $\delta 7.72$ and $\delta 6.76(J=2 \mathrm{~Hz})$ from the furan ring protons, 2 doublets with larger coupling constants at $\delta 6.21$ and $\delta 7.91(\mathrm{~J}=10 \mathrm{~Hz})$ from the lactone ring and a singlet at $\delta 6.85$. Compared to the NMR spectrum of imperatorine the furocoumarin protons agree with those of product 1 , however, no signals from side-chain protons can be observed.
Based on this the structure assigned to product 1 is that of 8-hydroxypsoralen (xanthotoxol). This is confirmed by the $\mathrm{OH}$-function observed in the IR spectrum at $3500 \mathrm{~cm}^{-1}$ and the mass spectrum which showed a parent peak with $m / e=202$. The NMR spectrum of product 2 also showed the signals of the furocoumarin ring system protons: two doublets at $\delta 7.82$ and $\delta 6.90(J=2 \mathrm{~Hz})$ of the furan ring protons, two doublets at $\delta 6.33$ and $\delta 8.01(J=10 \mathrm{~Hz})$ of the lactone ring protons and a singlet at $\delta 7.52$. Further are observed two broad singlets at $\delta 6.12$ and $\delta 5.92$ each representing one proton, a two proton singlet at $\delta 5.60$ and a three proton singlet at $\delta 1.88$. The structure of the ketone product of isogosferol is in agreement with this NMR spectrum. The signals at $\delta 6.12$ and $\delta 5.92$ are due to the vinylic protons. These are broadened by geminal coupling.

The chemical shifts of the vinylic protons agree with those of the model compound 2-methyl-1-buten-3-one (Jackman and Sternhell [21]). The singlets at $\delta 5.60$ and $\delta 1.88$ can be assigned to the methylene and methyl protons respectively. The IR spectum of product 2 shows strong absorption at $1720 \mathrm{~cm}^{-1}$, probably from the ketone function, but this absorption coincides with that of the lactone group, which is observed in the IR spectrum of imperatorine at $1710 \mathrm{~cm}^{-1}$. The structure assigned to product 2 is confirmed by the parent peak in the mass spectrum of $m / e=284$. The NMR spectrum of product 3 also shows the signals of the intact furocoumarin ring system: Two doublets at $\delta 7.84$ and $\delta 6.85(\mathrm{~J}=2 \mathrm{~Hz})$, two doublets at $\delta 6.28$ and $\delta 7.92$ $(J=10 \mathrm{~Hz})$ and a singlet at $\delta 7.52$. Further are observed two broad singlets each representing one proton at $\delta 5.11$ and $\delta 4.93$, a three proton multiplet around $\delta 4.40$ and a three proton singlet at $\delta 1.80$. The structure of isogosferol agrees with this NMR spectrum: the broad singlets at $\delta 5.11$ and $\delta 4.93$ are from the vinylic protons (the NMR spectrum of the model compound 2-methyl-1-penten-3-ol shows two broad singlets at $\delta 4.76$ and $\delta 4.87$ ). The multiplet around $\delta 4.40$ is from the three adjacent methylenecarbinol protons of the side-chain. Chatterjee et al. [11] also report that the corresponding $\mathrm{H}$-signals in the NMR spectrum of pabulenol (三gosferol, structure IV) are not resolved and appear as a multiplet around $\delta 4.35$. The signal at $\delta 1.80$ is from the methyl group. Further confirmation of this structure comes from the IR spectrum (OH-function at $3500 \mathrm{~cm}^{-1}$ ) 
and from the mass spectrum: parent peak at $m / e=$ 286. In further experiments these products have been used as reference compounds. The involvement of ${ }^{1} \mathrm{O}_{2}$ in the formation of these products, especially isogosferol and isogosferone was studied with two frequently used diagnostic tests for ${ }^{1} \mathrm{O}_{2}$ : the $\mathrm{D}_{2} \mathrm{O}$ effect and the effect of the ${ }^{1} \mathrm{O}_{2}$-quencher DABCO. In deuterated solvents the life time of ${ }^{1} \mathrm{O}_{2}$ is increased (Merkel and Kearns [20]), therefore reactions in which ${ }^{1} \mathrm{O}_{2}$ is involved are accelerated. In Fig.1 and Fig. 2 the effect of $\mathrm{D}_{2} \mathrm{O}$ in the solvent is shown on

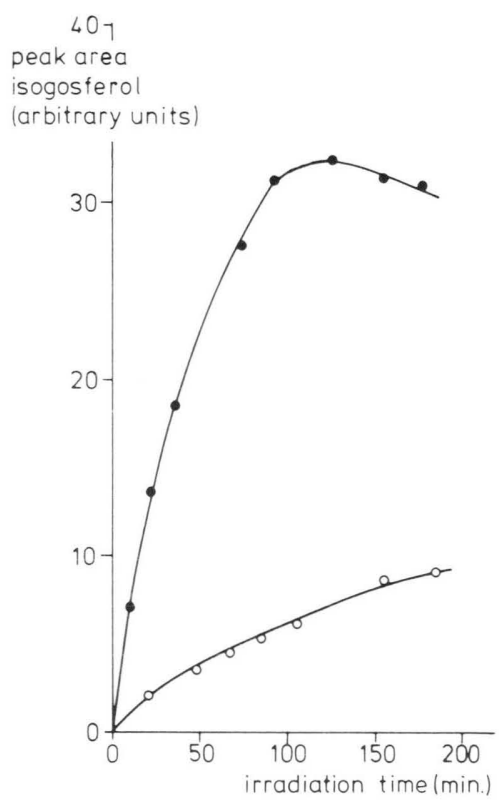

Fig. 1. $\mathrm{D}_{2} \mathrm{O}$ effect on the methylene blue sensitized formation of isogosferol from imperatorine. Iradiation mixture: methylene blue $(0.47 \mathrm{mM})$, imperatorine $(0.18 \mathrm{mM})$, solvent: $\mathrm{D}_{2} \mathrm{O} / \mathrm{MeOH}=5 / 1(\bullet), \mathrm{H}_{2} \mathrm{O} / \mathrm{MeOH}=5 / 1(\bigcirc)$. Irradiation in $3 \mathrm{ml}$ quartz cuvet with $1000 \mathrm{~W} \mathrm{HgXe} \mathrm{lamp} \mathrm{via} 1 \mathrm{~cm}$ path length $0.1 \% \mathrm{~K}_{2} \mathrm{Cr}_{2} \mathrm{O}_{7}$ filter solution $(\lambda>440 \mathrm{~nm})$ with continuous oxygenation.

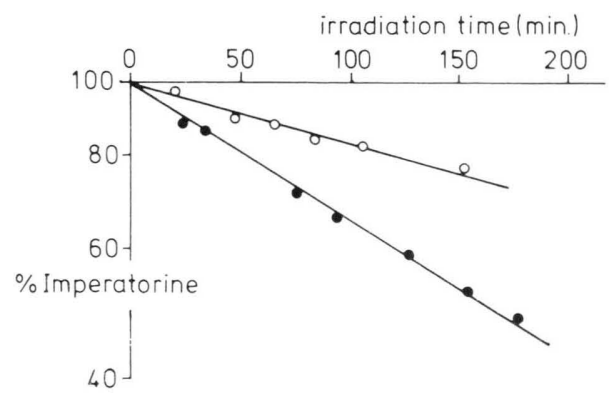

Fig. 2. $\mathrm{D}_{2} \mathrm{O}$ effect on the methylene blue sensitized imperatorine decomposition. Conditions as in Fig. 1. Solvent: $\mathrm{D}_{2} \mathrm{O} / \mathrm{MeOH}=5 / 1(\bullet), \mathrm{H}_{2} \mathrm{O} / \mathrm{MeOH}=5 / 1(\bigcirc)$.

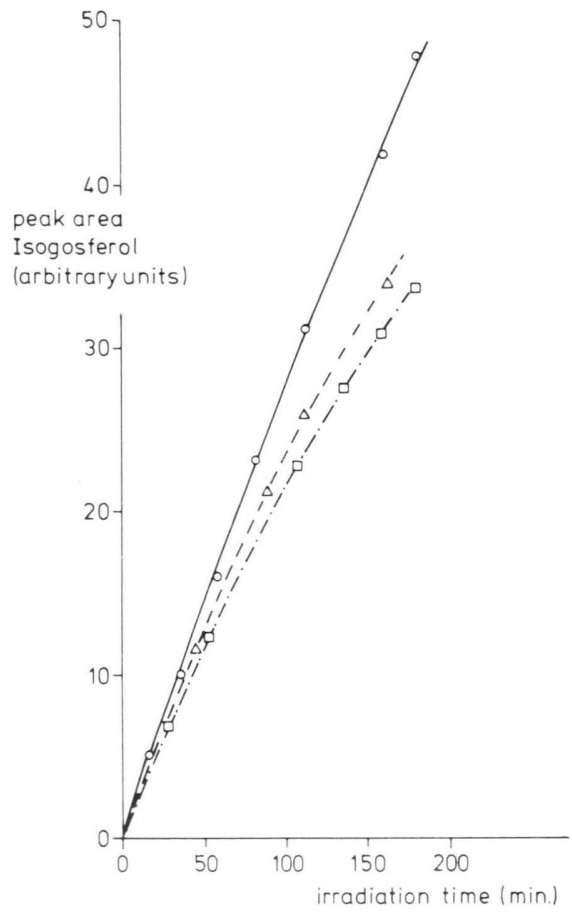

Fig. 3. Effect of ${ }^{1} \mathrm{O}_{2}$ quencher DABCO on the methylene blue sensitized formation of isogosferol from imperatorine. Irradiation mixture: methylene blue $(0.70 \mathrm{mM})$, imperatorine $(1.9 \mathrm{mM})$, solvent $\mathrm{H}_{2} \mathrm{O} / \mathrm{MeOH}=1 / 1$. $-\mathrm{O}-$ no

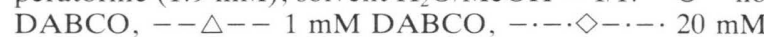
DABCO. Irradiation conditions as in Fig. 1.

the formation of isogosferol and decomposition of imperatorine respectively, in a methylene blue sensitized irradiation with visible light. The decomposition of imperatorine as well as the formation of isogosferol and isogosferone (not shown) are accelerated when $\mathrm{D}_{2} \mathrm{O}$ is present in the solvent. The amount of isogosferol reaches a maximum and decreases thereafter. This indicates the photochemical instability of isogosferol under the experimental conditions.

In Fig. 3 the effect of the ${ }^{1} \mathrm{O}_{2}$ quencher DABCO on the formation of isogosferol is shown. $\mathrm{DABCO}$ is considered as a physical quencher of ${ }^{1} \mathrm{O}_{2}$ and is stable under many experimental conditions (Ouannès and Wilson [22]). In the presence of DABCO the amount of formed isogosferol is decreased but the effect is small. This is probably caused by the relatively high concentration $(1.9 \mathrm{mM})$ of the chemical quencher for ${ }^{1} \mathrm{O}_{2}$ : imperatorine. Under this condition a competition for quenching of ${ }^{1} \mathrm{O}_{2}$ occurs between imperatorine and $\mathrm{DABCO}$. From the $\mathrm{D}_{2} \mathrm{O}$ effect and the effect of $\mathrm{DABCO}$ can be concluded that in the 


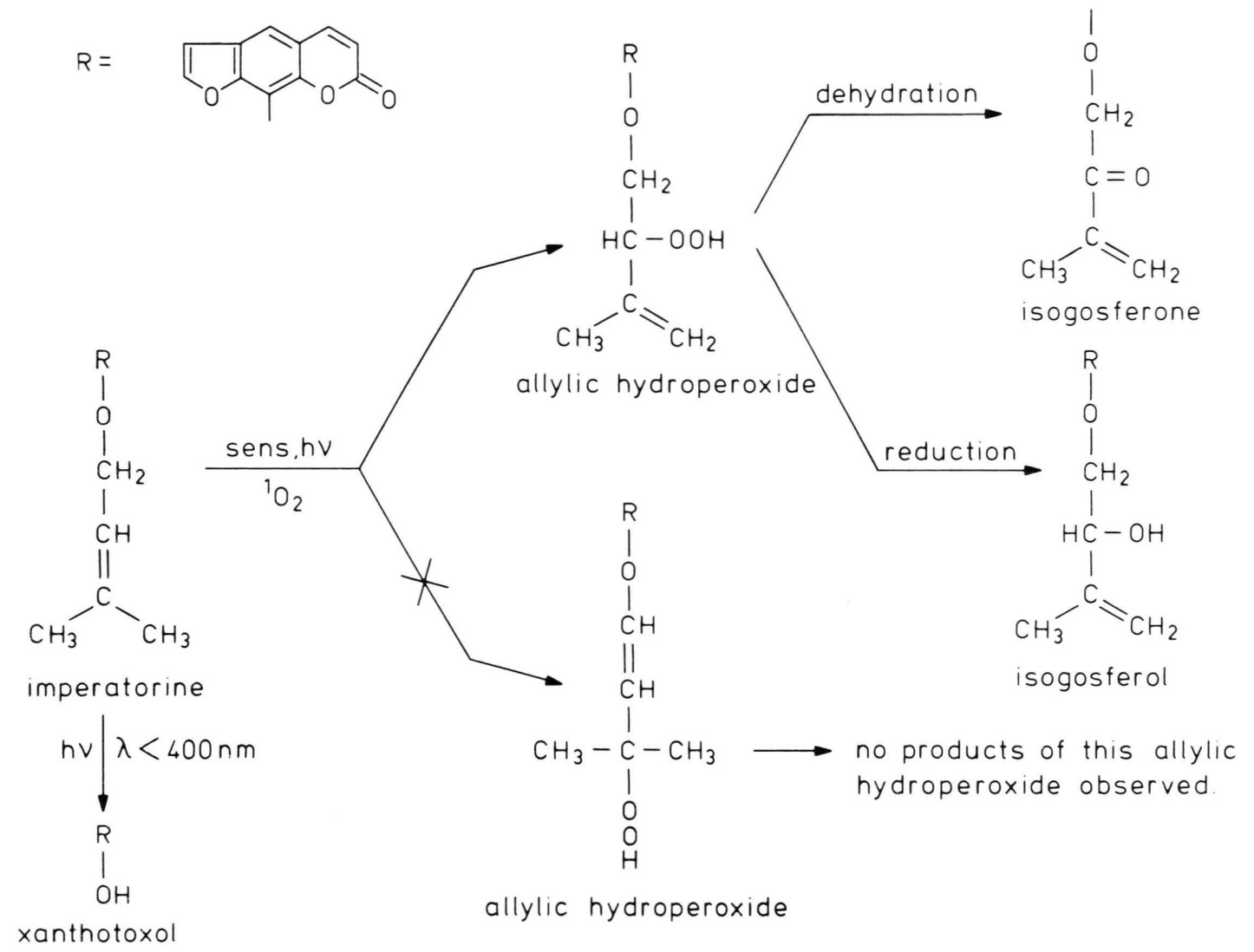

Scheme 1. Photoproducts of imperatorine.

case of methylene blue sensitization ${ }^{1} \mathrm{O}_{2}$ is involved in the imperatorine decomposition and the formation of isogosferol and isogosferone. Under these conditions formation of xanthotoxol is minor. A methylene blue sensitized irradiation of isogosferol did not yield isogosferone. As in the formation of the structurally related compounds: isogosferol and isogosferone ${ }^{1} \mathrm{O}_{2}$ appears to be involved, it is likely that both compounds are formed from the same allylic hydroperoxide, being a primary product of the enereaction (Gollnick and Kuhn [16]).

As is shown in Scheme 1 isogosferol is formed by reduction of this allylic hydroperoxide and isogosferone by dehydration, which are commonly observed secondary reactions of allylic hydroperoxides (Gollnick and Kuhn [16]). No indications are observed for the formation of products derived from the allylic hydroperoxide with oxygen at the methyl groups substituted carbon (see Scheme 1). It is inter- esting that the corresponding hydroxylcompound is not reported as naturally occuring. The dye-sensitized oxidation of the structurally related 3-methyl2-butenyl side-chain of various coumarine compounds has been reported by serveral authors (Murray and Forbes [23]; Guise et al. [24]; Fourrey et al. [25] and Raj et al. [26]). In these oxidations attack of oxygen at the C-3 carbon atom is observed as the main reaction, except in the case of suberine sensitized with bengal rose, in which case the product with a hydroxylgroup at the C-3 carbon is formed less than that with a hydroxyl group at C-2 (Raj et al. [26]). It is possible that with the 3-methyl-2-butenyl side-chain C-2 is sterically hindered for attack of ${ }^{1} \mathrm{O}_{2}$. As imperatorine has an additional oxygen atom in the side-chain C-2 is more easily accesible for attack of ${ }^{1} \mathrm{O}_{2}$.

Further experiments were performed to investigate the possibility that naturally occurring 
furocoumarins acts as ${ }^{1} \mathrm{O}_{2}$ source in this oxidation. In view of this, the extent of ${ }^{1} \mathrm{O}_{2}$ production by imperatorine itself was investigated with DOPA as ${ }^{1} \mathrm{O}_{2}$ acceptor. DOPA was useful to assay the extent of ${ }^{1} \mathrm{O}_{2}$ production of a range of furocoumarins (de $\mathrm{Mol}$ et al. [17]). The ${ }^{1} \mathrm{O}_{2}$ production of imperatorine relative to that of 8 -methoxypsoralen is 0.85 .

Upon irradiation of imperatorine with $350 \mathrm{~nm}$ light with $\mathrm{D}_{2} \mathrm{O}$ in the solvent both DOPA decomposition as well as imperatorine decomposition are increased (Fig. 4). After longer irradiation times the DOPA decomposition deviates from first order kinetics and the rate decreases. This is caused by the decomposition of imperatorine, the sensitizer for DOPA decomposition. In Table I the value for ${ }^{1} \mathrm{O}_{2}$

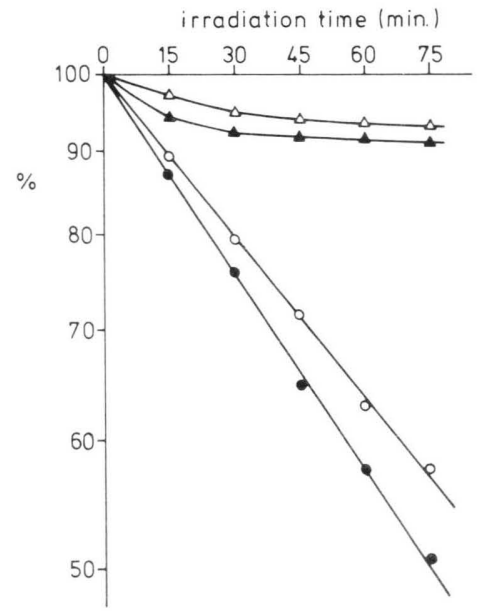

Fig. 4. $\mathrm{D}_{2} \mathrm{O}$ effect on the decomposition of imperatorine (O) and the imperatorine sensitized decomposition of dopa $(\triangle)$. Irradiation mixture: imperatorine $(0.4 \mathrm{mM})$, dopa (0.7 mM), solvent: $\mathrm{H}_{2} \mathrm{O} / \mathrm{MeOH}=1 / 1$ (open symbols), $\mathrm{D}_{2} \mathrm{O} / \mathrm{MeOH}=1 / 1$ (closed symbols). Irradiation with 4 lamps RUL $3500 \AA$ A. Light intensity $2.0 \mathrm{~mW} / \mathrm{cm}^{2}$. Oxygenation during $1 \mathrm{~min}$ after every $15 \mathrm{~min}$. production of imperatorine is included together with those for a range of furocoumarins as previously determined (de Mol et al. [17]). Also included in Table I is the skin photosensitizing activity of these furocoumarins as determined by Pathak and Fitzpatrick [27]. The extent of ${ }^{1} \mathrm{O}_{2}$ production agrees fairly well with the skin sensitizing activity of imperatorine: in Fig. 5 imperatorine is included in the previously

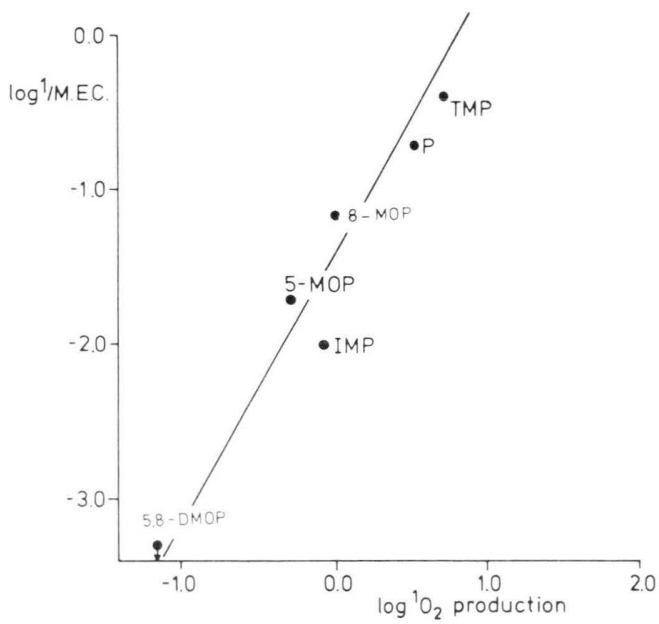

Fig. 5. Relationship between ${ }^{1} \mathrm{O}_{2}$ production and literature data for minimal erythema concentration (M.E.C.) for topical application on albino guinea pig skin (Pathak and Fitzpatrick [27]) for various furocoumarins (see also Table I). Correlation coefficient $=0.971, n=7$.

reported relationship between ${ }^{1} \mathrm{O}_{2}$ production and skin photosensitizing activity of a range of furocoumarins (de Mont et al. [17]).

Upon irradiation of imperatorine with $350 \mathrm{~nm}$ light decomposition of imperatorine occurs. Under these conditions xanthotoxol is formed next to other products (Scheme 1). Isogosferone and isogosferol cannot be detected as photoproducts. Sensitization

\begin{tabular}{llcc}
\hline & & & $\begin{array}{c}\text { M.E.C. } \\
(\mu \mathrm{g} / \mathrm{sq} . \text { inch })^{\mathrm{b}}\end{array}$ \\
& Relative ${ }^{\mathrm{l}} \mathrm{O}_{2}$ Production $\pm \mathrm{SD}$ & 2.5 \\
Trimethylpsoralen (TMP) & $5.3 \pm 0.1^{\mathrm{a}}$ & 5 \\
Psoralen (P) & $3.3 \pm 0.1^{\mathrm{a}}$ & 15 \\
8-Methoxypsoralen (8-MOP) & & $1^{\mathrm{a}}$ & 100 \\
Imperatorine (IMP) & $0.85 \pm 0.02$ & 50 \\
5-Methoxypsoralen (5-MOP) & $0.52 \pm 0.02^{\mathrm{a}}$ & $>2000$ \\
5,8-Dimethoxypsoralen (5,8-DMOP) & $0.069 \pm 0.001^{\mathrm{a}}$ & \\
\hline
\end{tabular}

Table I. Extent of ${ }^{1} \mathrm{O}_{2}$ production by various furoumarins relative to 8-methoxypsoralen and their minimal erythema concentration (M.E.C.) for topical application on albino guinea-pig skin.

\footnotetext{
a de Mol et al. [17];

${ }^{b}$ Pathak and Fitzpatrick [27].
} 
with the more potent ${ }^{1} \mathrm{O}_{2}$ generator trimethylpsoralen (see Table I) did not alter this product formation.

Upon irradiation with $360 \mathrm{~nm}$ light xanthotoxol is formed from photo-activated imperatorine. However, in addition to this also ${ }^{1} \mathrm{O}_{2}$ is involved in the imperatorine decomposition as appears from the $\mathrm{D}_{2} \mathrm{O}$ effect on the imperatorine decomposition shown in Fig. 4. That the expected ${ }^{1} \mathrm{O}_{2}$ oxidation products isogosferol and isogosferone are not observed is probably caused by their photochemical instability, as these products also absorb light of $360 \mathrm{~nm}$. From these results it is expected that if isogosferol is formed in plants from imperatorine by a photochemical process sensitization with light of long wavelengths $(\lambda>\sim 400 \mathrm{~nm})$ is involved. This means that other sensitizers than imperatorine or other furocoumarins are responsible. In plants chlorophyll is an effective sensitizer for photo-oxidation of organic substrates for the effects of which plants have to be protected by ${ }^{1} \mathrm{O}_{2}$ quenching carotenoids (Koka and Song [28]). Chlorophyll absorbs wavelengths $<700 \mathrm{~nm}$. Experiments were performed to investigate the ability of the chlorophyll chromophore to act as a sensitizer for ${ }^{1} \mathrm{O}_{2}$ oxidation of imperatorine. The chlorophyll chromophore used in this study is a commercial copper containing product in which the phytyl and methyl esters are replaced by $\mathrm{Na}$ by careful alkaline hydrolysis (Strell and Zuther [29]). The product so obtained is called chlorophyllin and is water-soluble, which makes it suitable for experiments with $\mathrm{D}_{2} \mathrm{O}$. Irradiations of the chlorophyll chromophore were performed with

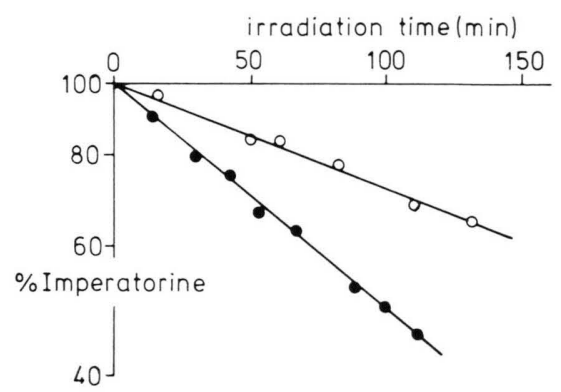

Fig. 6. $\mathrm{D}_{2} \mathrm{O}$ effect on the chlorophyllin sensitized decomposition of imperatorine. Irradiation mixture: copper complex of the sodium salt of chlorophyllin $(1 \mathrm{mg} / \mathrm{ml})$, imperatorine $(1.2 \mathrm{mM})$, solvent: $\mathrm{H}_{2} \mathrm{O} / \mathrm{MeOH}=1 / 1(\mathrm{O})$, $\mathrm{D}_{2} \mathrm{O} / \mathrm{MeOH}=1 / 1(\bullet)$. Irradiation in $3 \mathrm{ml}$ quartz cuvet with $1000 \mathrm{~W} \mathrm{HgXe}$ lamp via $1 \mathrm{~cm}$ path length $0.1 \%$ $\mathrm{K}_{2} \mathrm{CrO}_{4}$ filter solution $(\lambda>400 \mathrm{~nm})$ with continous oxygenation. visible light $(\lambda>400 \mathrm{~nm})$, to avoid direct irradiation of imperatorine or its oxidation products. As in the case of methylene blue, sensitization with the chlorophyll chromophore leads to accelerated decomposition of imperatorine (Fig. 6) as well as to formation of isogosferol and isogosferone in the presence of $\mathrm{D}_{2} \mathrm{O}$ (Fig. 7). The amounts of isogosferol and isogosferone reach a maximum indicating their instability under the experimental conditions. The accelerated post-maximum decrease of especially isogosferol with $\mathrm{D}_{2} \mathrm{O}$ indicates that ${ }^{1} \mathrm{O}_{2}$ is involved in the decomposition of this olefinic compound.

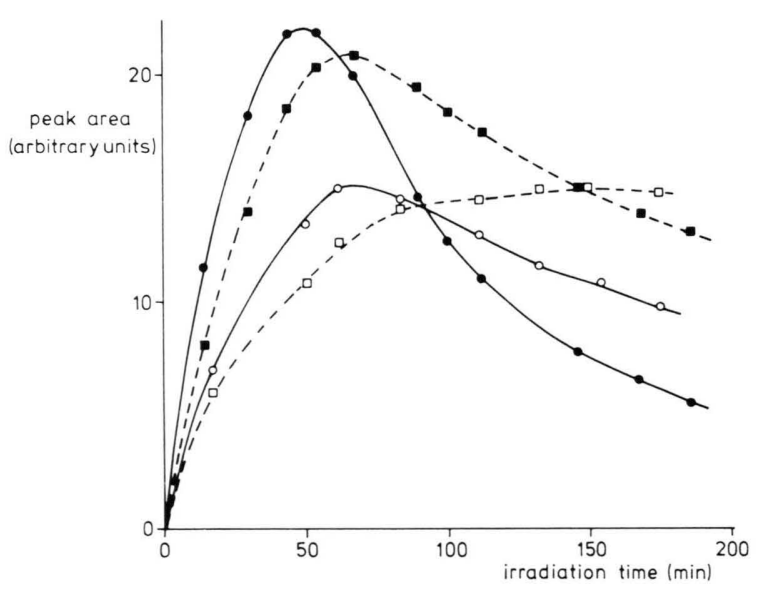

Fig. 7. $\mathrm{D}_{2} \mathrm{O}$ effect on the chlorophyllin sensitized formation of isogosferol $(\bigcirc)$ and isogosferone $(\square)$ from imperatorine. Conditions as in Fig. 6. Solvent: $\mathrm{H}_{2} \mathrm{O} / \mathrm{MeOH}=1 / 1$ (open symbols), $\mathrm{D}_{2} \mathrm{O} / \mathrm{MeOH}=1 / 1$ (closed symbols).

Our study demonstrates that the possibility exists that isogosferol is formed in plants in vivo from oxidation of imperatorine by ${ }^{1} \mathrm{O}_{2}$. In particular irradiation with visible light and sensitization by chlorophyll may be involved in this process. It can be expected that naturally occuring carotenoids suppress the formation of ${ }^{1} \mathrm{O}_{2}$ oxidation products of imperatorine. The influence of $\beta$-carotene on the chlorophyll sensitized oxidation of imperatorine was investigated. Because of the solubility of $\beta$-carotene experiments were performed in the lipophylic solvent toluene. The chlorophyllin sensitizer is not soluble in toluene, therefore a product containing intact chlorophyll was used. In Fig. 8 and Fig. 9 the influence of $\beta$-carotene is shown on the chlorophyll sensitized imperatorine decomposition and product formation, respectively. 


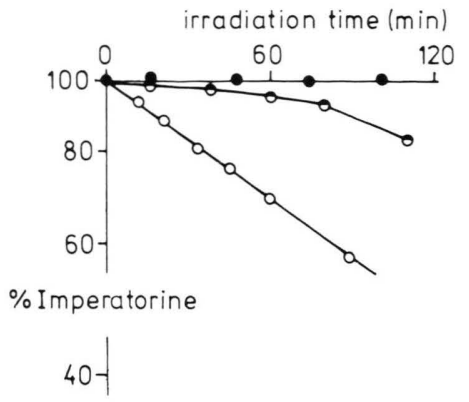

Fig. 8. Influence of $\beta$-carotene on the chlorophyll sensitized decomposition of imperatorine. Irradiation mixture: imperatorine $(1.4 \mathrm{mM})$ and chlorophyll $(7.5 \mathrm{mM})$ in toluene, no $\beta$-carotene $(\bigcirc), 0.35 \mathrm{mM} \beta^{\prime}$-carotene $(\bullet)$ and $2.1 \mathrm{mM} \beta$-carotene $(\bullet)$. Irradiation conditions as in Fig. 6.

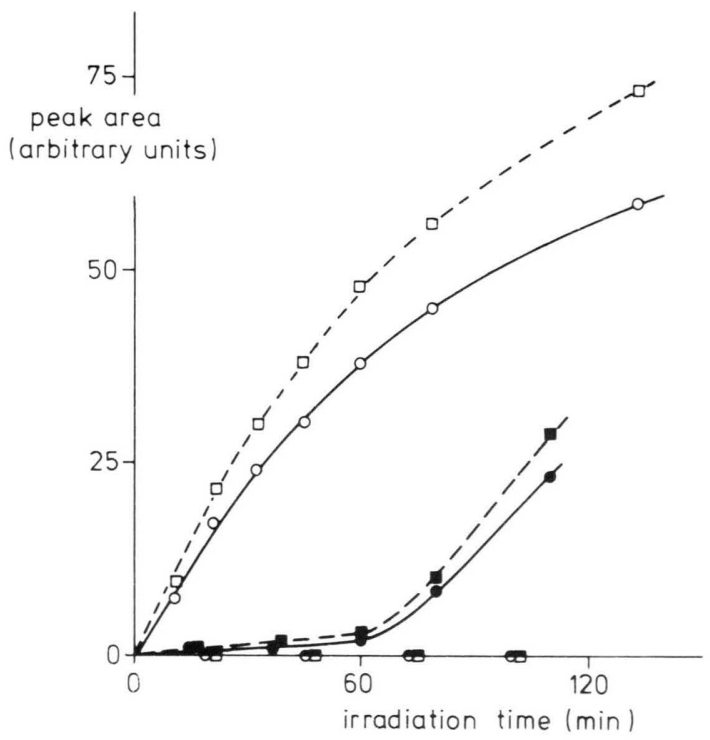

Fig. 9. Influence of $\beta$-carotene on the chlorophyll sensitized formation of isogosferol $(\bigcirc)$ and isogosferone $(\square)$. Conditions as in Fig. 8. Open symbols: no $\beta$-carotene, closed symbols: $2.1 \mathrm{mM} \beta$-carotene, half filled symbols: $0.35 \mathrm{mM} \beta$-carotene.
The presence of more than $2 \mathrm{mM} \beta$-carotene prevents imperatorine decomposition completely. Three factors contribute to this phenomenon:

1) quenching of the chlorophyll sensitizer by $\beta$ carotene, which occurs at a very high rate (Foote [30]);

2) quenching of ${ }^{1} \mathrm{O}_{2}$ by $\beta$-carotene;

3) absorption of actinic light by $\beta$-carotene.

In the case of an initial $\beta$-carotene concentration of $0.35 \mathrm{mM}$ little product formation is found (Fig. 9). After $\sim 60 \mathrm{~min}$ irradiation time imperatorine decomposition (Fig. 8) and product formation are accelerated. This is caused by photo-chemical decomposition of $\beta$-carotene which appears from the change in colour of the irradiated solution. Compared to methanol/water in toluene more isogosferone than isogosferol is formed. This indicates that the solvent influence the secondary reactions of the allylic hydroperoxide.

To what extent carotenoids may suppress the formation of ${ }^{1} \mathrm{O}_{2}$ oxidation products of imperatorine in vivo depends on the relative concentrations of reactants and on the competition for ${ }^{1} \mathrm{O}_{2}$ quenching between imperatorine and carotenoids. From this study it appears that in an in vitro model system naturally occuring isogosferol can be formed from ${ }^{1} \mathrm{O}_{2}$ oxidation of imperatorine. As the ketone product isogosferone is formed under similar conditions it should be of interest to study the presence of this compound in isogosferol containing plants.

We thank Mr. J. J. van Houtte and Mr. A. W. M. Lefeber for recording of mass and NMR spectra respectively. One of us, J. R. thanks the "Deutsche Forschungsgemeinschaft" for financial support.
[1] C.M. Andrade da Mata Rezende, M. V. von Bülow, O. R. Gottlieb, S. Lamêgo Vieira Pinho, and A. I. da Rocha, Photochemistry 10, 3167 (1971).

[2] J. Reisch and K. Szendrei, Arch. Pharm. (Weinheim) 308, 983 (1975).

[3] D. Herlem, Y. Hubert-Brierre, F. Khuong-Huu, and R. Goutarel, Tetrahedron 29, 2195 (1973).

[4] T. Kusumi, T. Kishi, H. Kakisawa, and T. Kinoshita, J. Chem. Soc. Perkin I 1976, 1716.

[5] S. P. Singh, V. I. Stenberg, and S. S. Parmar, Chem. Rev. 80, 269 (1980).
[6] G. O. Schenk and K. Ziegler, Naturwissenschaften 32, 157 (1944) and later publications.

[7] T. Matsuura, Tetrahedron 33, 2869 (1977).

[8] A. Z. Abyshev, Khim. Prir. Soedin. 6, 708 (1974); C. A. 82, $135682 n$.

[9] A. Z. Abyshev, Khim. Prir. Soedin. 10, 83 (1974); C. A. 80, 120816 u.

[10] A. Z. Abyshev, Khim. Prir. Soedin. 16, 830 (1980); C. A. 94, $171048 \mathrm{~s}$

[11] A. Chatterjee, J. Banerji, and S. C. Basa, Tetrahedron 28, 5175 (1972). 
[12] A. G. Gonzalez, R. E. Reyes, and J. F. Hernandez, An. Quim. 69, 253 (1973); C. A. 78, 147839z.

[13] A. G. Gonzalez, J. T. Barroso, J. R. Luis, and F. Rodriguez Luis, An. Quim. 70, 369 (1974); C. A. 81, $117051 \mathrm{f}$.

[14] A. G. Gonzalez, J. T. Barroso, R. J. Cardona, J. M. Medina, and F. Rodriguez Luis, An. Quim. 73, 1188 (1977); C. A. 89, 193816q.

[15] E. Varga, J. Simokovics, K. Szendrei, and J. Reisch, Fitoterapia 50, 259 (1979).

[16] K. Gollnick and H. J. Kuhn, in "Singlet Oxygen" (eds. H. H. Wasserman and R. W. Murray) Chapt. 8, p. 287, Academic Press, New York (1979).

[17] N. J. de Mol and G. M. J. Beijersbergen van Henegouwen, Photochem. Photobiol. 33, 815 (1981).

[18] N. I. Krinsky, in "Singlet Oxygen" (eds. H. H. Wasserman and R. W. Murray) Chapt. 12, p. 596, Academic Press, New York (1979).

[19] N. J. de Mol, G. M. J. Beijersbergen van Henegouwen, and K. W. Gerritsma, Photochem. Photobiol. 29, 7 (1979).

[20] P. B. Merkel and D. R. Kearns, J. Am. Chem. Soc. 94, 7244 (1972).
[21] L. M. Jackman and S. Sternhell, in "Applications of nuclear magnetic resonance spectroscopy in organic chemistry" 2nd ed. p. 171, Pergamon Press, Oxford (1969)

[22] C. Ouannès and T. Wilson, J. Am. Chem. Soc. 90, 6527 (1968).

[23] R. D. H. Murray and I. T. Forbes, Tetrahedron 34, 1411 (1978).

[24] G. B. Guise, E. Ritchie, R. G. Senior, and W. C. Taylor, Aust. J. Chem. 20, 2429 (1967).

[25] J. L. Fourrey, J. Rondest, and J. Polonsky, Tetrahedron 26, 3839 (1970).

[26] K. Raj, R. S. Kapil, and S. P. Popli, J. Ind. Chem. 13, 404 (1974).

[27] M. A. Pathak and T. B. Fitzpatrick, J. Invest. Dermatol. 32, 255 (1959).

[28] P. Koka and P.-S. Song, Photochem. Photobiol. 28, 509 (1978).

[29] M. Strell and F. Zuther, Liebigs Ann. Chem. 612, 264 (1958).

[30] C. S. Foote, in "Free Radicals in Biology", Vol. II, Chapt. 3, p. 85 (ed. W. A. Pryor), Academic Press, New York (1976). 